\title{
CASEREPORT
}

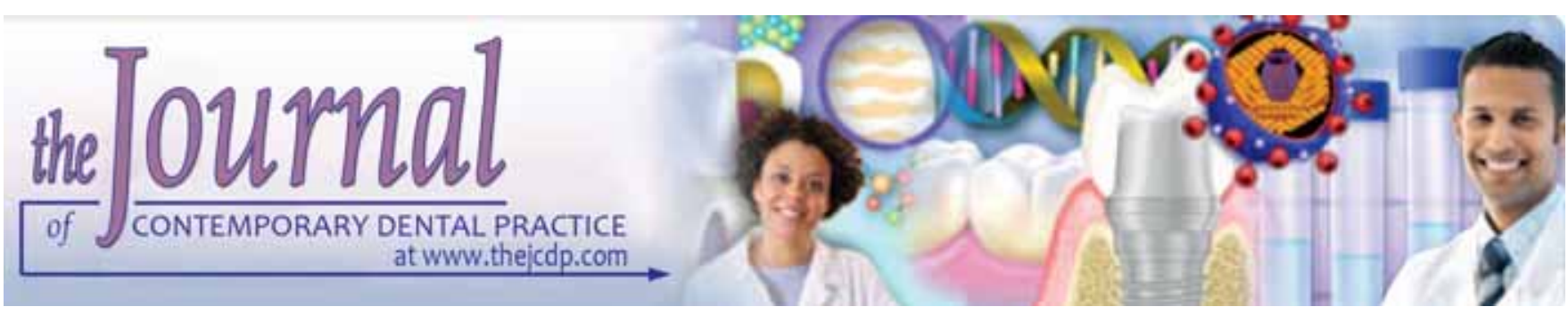

\section{Morphologic Variations of Maxillary Molars Palatal Root and the Importance of Its Knowledge for Endodontic Practice: A Case Series}

\author{
Roberta Kochenborger Scarparo, Letícia Pereira, Diana Moro, Grasiela Gründling \\ Maximiliano Gomes, Fabiana Soares Grecca
}

\begin{abstract}
Aim: The present report describes and discusses root canal variations in the internal morphology of maxillary molars.
\end{abstract}

Background: Dental internal anatomy is directly related to all the technical stages of the endodontic treatment. Even though, in some situations a typical anatomical characteristics can be faced, and the professional should be able to identify them.

Case descriptions: This clinical report describes five cases with different pulpar and periapical diagnostics where the endodontic treatment was performed, in which during the treatment the unusual occurrence of two or three canals in the palatal root 'or even two distinct palatal roots' of first and second maxillary molars, were described and important details for achieving treatment success were discussed.

Conclusion: The knowledge of tooth internal anatomy must be considered during clinical and radiographic examinations. This should be valued not only to find atypical canals but also to enable calcified canals cleaning and shaping, once they are frequently omitted during endodontic therapy.

Clinical significance: Anatomic variations can occur in any tooth, and palatal roots of maxillary first and second molars are no exception. The complexity of the root canal system and the importance of identifying its internal anatomy for planning endodontic treatment increase the chances of success.

Keywords: Unusual canal configuration, Anatomy, Maxillary molar, Palatal root, Endodontics.

How to cite this article: Scarparo RK, Pereira L, Moro D, Gründling G, Gomes M, Grecca FS. Morphologic Variations of Maxillary Molars Palatal Root and the Importance of Its Knowledge for Endodontic Practice: A Case Series. J Contemp Dent Pract 2011;12(2):138-142.

Source of support: Nil

Conflict of interest: None declared

\section{INTRODUCTION}

The knowledge of internal anatomy and its variations is of paramount importance in endodontics, as non-endodontically treated of root canals greatly decreases the chances of treatment success. ${ }^{1-5}$ The maxillary first molar usually presents three roots and four canals (one canal in the palatal root, two in the mesiobuccal root and one in the distal root). ${ }^{4}$ On the contrary, the maxillary second molar often shows three roots and three canals (one canal in the palatal root, one in the mesiobuccal root and one canal in the distobuccal root). ${ }^{4}$ However, due to the complexity of the root canal system, some variations have been reported..$^{1-6}$

Clinical studies confirm the presence of four root canals on maxillary first molars as the anatomical feature most frequently found. Wolcott et $\mathrm{al}^{7}$ observed two canals in the mesiobuccal root in $61.1 \%$ of cases, and Buhrley et $\mathrm{al}^{3}$ in $71.1 \%$. In contrast to these findings, the frequency of reports of two palatal canals is low. Reports of two distinct palatal roots in maxillary molars are rare as well. ${ }^{5,6}$

In an ex vivo study, Sert and Bayirli ${ }^{8}$ have assessed 200 cleared maxillary first molars, being two canals observed in $93.5 \%$ of the mesiobuccal roots. Of these, $60.5 \%$ presented a single apical foramen and $39.50 \%$ presented two independent foramens. On the contrary, mesiodistal and palatal roots showed, in 90.50 and $94.50 \%$ of the sample, a single canal. The cases in which the palatal root presented more than one canal, only $4 \%$ also showed more than one foramen.

Some quite atypical cases in maxillary second molars have already been described. Pasternack-Jr et al ${ }^{9}$ reported a case in which six root canals were identified. De Almeida Gomes, Maniglia-Ferreira and dos Santos ${ }^{5}$ reported a case of two palatal roots in a second maxillary molar. Similarly, the clinical cases described below present the unusual occurrence of two palatal roots or two canals in the palatal root of first and second molars. Given the complexity of 
the root canal system and the importance of identifying its internal anatomy for planning endodontic treatment, the aim of this study is to discuss, based on a case series, atypical variations of the anatomy of maxillary molars focusing on its palatal root.

\section{CASE REPORTS}

\section{Case 1}

An 80-year-old male patient sought treatment in a private practice complaining of moderate intensity, spontaneous and diffuse pain in the posterior right maxilla. The clinical examination showed an extensive carious lesion in the second maxillary right molar. The tooth was responsive to cold test, and radiographic examination did not show periapical radiolucency. Irreversible pulpitis was diagnosed and endodontic treatment indicated.

After anesthesia and rubber dam placement, the caries lesion was removed and the endodontic access performed. The presence of two distinct palatal canals and two distinct buccal canals on pulp chamber floor (Fig. 1A) was clear, even without the radiographic identification of additional canals being performed at first (Fig. 1B). Crown-down instrumentation and root canal filling by means of guttapercha lateral condensation were performed (Fig. 1C). During instrumentation and canal fillings, the occurrence of two independent foramens was identified.

Tooth was sealed with glass ionomer cement (Vitro Fill, DFL, Brazil) and the patient was referred to the final restoration.

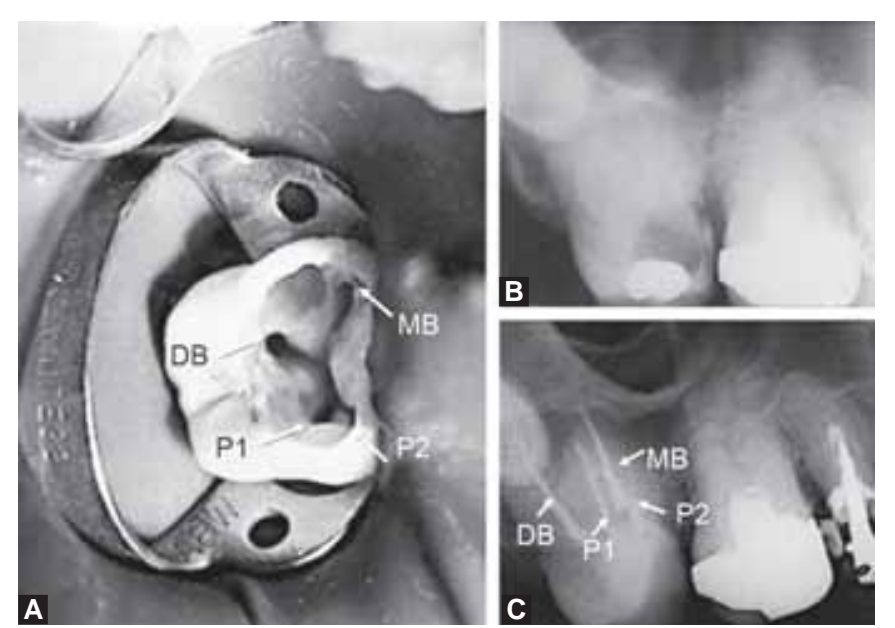

Figs $1 \mathrm{~A}$ to $\mathrm{C}$ : Endodontic access in case 1 showing the entrances of mesiobuccal (MB), distobuccal (DB) and two palatal canals (P1 and P2) in tooth 17: (A) Initial periapical radiography of case 1, (B) Final periapical radiography of case 1: The occurrence of mesiobuccal canal (MB), distobuccal canal (DB) and of two canals on the palatal root (P1 and P2) can be observed (C)

\section{Case 2}

A 16-year-old male patient was treated at the Brazilian Air force Hospital of Canoas. The patient presented severe pain and deep caries in the second maxillary right molar, suggesting irreversible pulpitis. Partial removal of coronal pulp had already been performed as a palliative treatment in previous appointment.

After clinical and radiographic examinations, anesthesia was performed and rubber dam was placed. The improvement of the endodontic access was performed.

Exploration of root canals was performed using K-files. A smooth roughness could be felt at the cervical third of the palatal canal, about $3 \mathrm{~mm}$ below the root canal entrance. The endodontic file was easily introduced into the irregular area found.

The presence of a second canal, with an independent foramen in the palatal root, was revealed by radiography for root length determination. Work lengths were set at 26 $\mathrm{mm}$ for both palatal canals, and $24 \mathrm{~mm}$ for mesiobuccal, mesiopalatal and distobuccal canals. The root canals preparation was performed manually using crown-down technique and $1 \%$ sodium hypochlorite.

The canals were filled using Tagger hybrid technique and an epoxy resin-based sealer (AH Plus, Dentsply Maillefer, Ballaigues, Switzerland). Tooth was sealed with glass ionomer cement (Vitro Fill, DFL, Brazil). After the conclusion of the endodontic treatment the patient was referred to the final restoration. The five root canals treated can be observed on Figure 2A.

\section{Case 3}

A 40-year-old female patient was sent for specialized endodontic treatment at the Brazilian Air force Hospital of Canoas. The patient presented an extensive resin restoration and referred intense spontaneous pain localized in the right maxillary first molar, which was unresponsive to cold tests. The presence of an acute endodontic abscess was diagnosed and endodontic treatment indicated.

Anesthesia, rubber dam placement and endodontic access were performed, allowing for abscess drainage and showing the presence of two distinct palatal canals and two distinct buccal canals on pulp chamber floor. Odontometric radiography clearly revealed two independent entrances and a unique foramen at the palatal root (Fig. 2B).

Root canals instrumentation was performed. Calcium hydroxide was used as a root canal dressing and a glass ionomer temporary restoration was placed.

On the second appointment, the patient referred pain remission, allowing root canal fillings procedures. The tooth 
was sealed with glass ionomer cement and the patient was referred to the final restoration. The five root canals treated can be observed on Figures 2A and C.

\section{Case 4}

A 37-year-old female patient sought treatment with history of pain in the second maxillary right molar. The tooth was unresponsive to cold test. Radiographic examination confirmed a radiolucent area in the palatal root, suggesting a necrotic pulp. After clinical and radiographic examinations, anesthesia was performed and rubber dam was placed. The improvement of the endodontic access was performed. Exploration of root canals was performed using K-files. The presence of second and third canals, with independents foramens in the palatal root was revealed by odontometric radiography. Root canals instrumentation was performed and calcium hydroxide was used as a root canal dressing. On the second appointment, the canals were filled using a zinc and oxide-eugenol-based sealer (EndoFill, Dentsply, Petropolis, Brazil) (Fig. 2D).
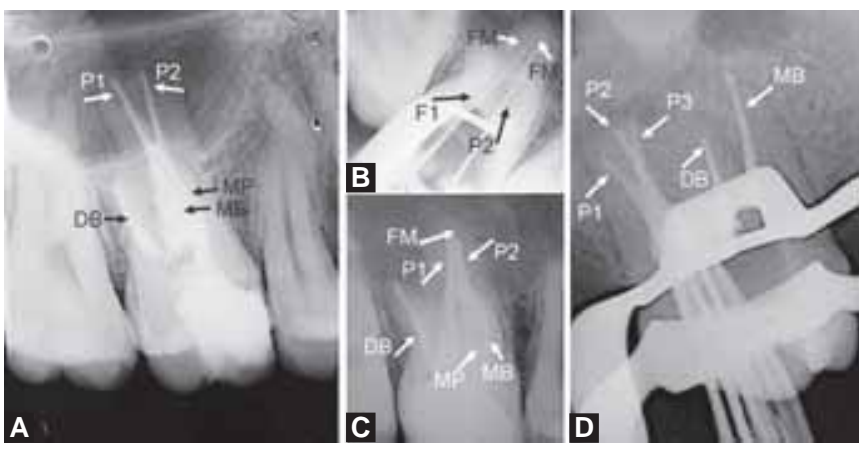

Figs 2A to D: Periapical radiographs of cases 2, 3 and 4: In case 2, the occurence of mesiobuccal and mesiopalatal canals (MB), distobuccal canals (DB) and of two canals on the palatal root (P1 and P2) can be observed. (A) In case 3, the radiography for the working length determination showed clearly independent entrances for the two palatal canals (P1 and P2) and an unique foramen at the palatal root (B) final periapical radiography of case 3 . (C) final periapical radiography of case 4-the occurrence of three canals on the palatal root (P1, P2 and P3) can be observed (D)

\section{Case 5}

A 36-year-old male patient sought treatment in the Medical and Dental Center of the Military Brigade-RS, with history of unsuccessful prosthetic treatment in the region of posterior right maxilla and indication of endodontic retreatment of the second maxillary right molar, which would be used as a prosthetic support. Clinical examination revealed the presence of poorly adopted fixed prosthesis, with the presence of extensive carious lesion recurrence under the prosthesis of the second maxillary right molar. There were no associated symptoms. Radiographic examination (Fig. 3A) confirmed a radiolucent area in the crown of the second maxillary right molar, under the prosthesis, compatible with a recurrent carious lesion. Radiographic examination also showed the presence of a short metallic post and the presence of a poor endodontic treatment, with incomplete endodontic filling. It was possible to observe the presence of four roots in this previous radiographic examination, and no periapical radiolucency was distinguished. After removal of the prosthesis, endodontic retreatment of the second maxillary right molar was indicated.

Anesthesia and rubber dam placement were performed, the caries lesion was removed and the endodontic access was accomplished. The presence of two distinct palatal canals, as well as two distinct buccal canals on pulp chamber floor was clear (Fig. 3D), confirming the previous radiographic suspect concerning the presence of four distinct roots. During the mesiobuccal canal exploration, it was possible to detect the presence of an insurmountable deviation, possibly caused by the prior endodontic intervention. Radiographic confirmation of root canals lengths was performed (Fig. 3B), and work lengths were set as $18.5 \mathrm{~mm}$ for mesiopalatal canal, $21.0 \mathrm{~mm}$ for distopalatal canal, $20.0 \mathrm{~mm}$ for mesiobuccal canal and 21.5 $\mathrm{mm}$ for distobuccal canal. Instrumentation was performed manually, using K-files and crown-down technique and $2.5 \%$ sodium hypochlorite. Calcium hydroxide was used as a root canal dressing and a glass ionomer temporary restoration was placed.

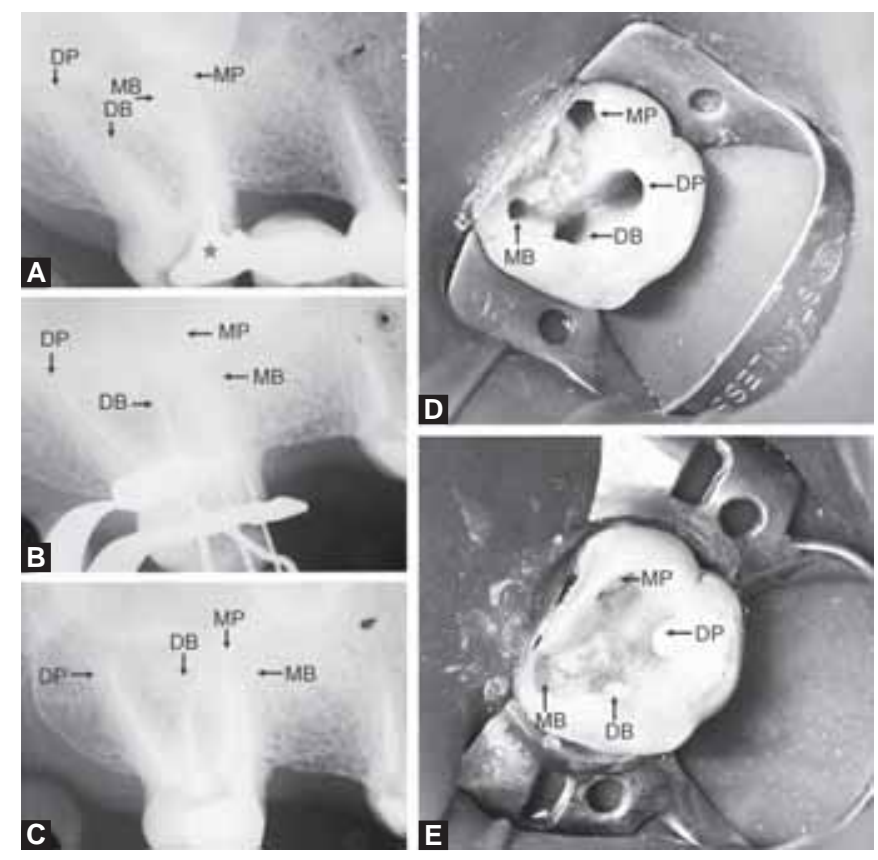

Figs $3 A$ to $E$ : Endodontic treatment in case 5 . Initial periapical radiography, $(\mathrm{A})$ the metallic post and four distinct roots in tooth 17: Mesiobuccal (MB), distobuccal (DB), mesiopalatal (MP) and distopalatal (DP). Odontometric $(\mathrm{B})$ and final $(\mathrm{C})$ radiographs were the occurrence of four distinct roots (MB, DB, MP and DP) can be observed. Clinical view of endodontic access (D) and filling (E) showing clearly independent entrances for the four root canals 
On the second appointment, the canals were filled (Figs 3C and $3 E$ ) using Tagger hybrid technique and an oxideeugenol-based sealer. Tooth was sealed with glass ionomer cement and the patient was referred to continue the prosthetic rehabilitation.

\section{DISCUSSION}

Although the observation of two distinct palatal roots or two or more canals in the palatal root of maxillary molars is rare, it has already been described., ${ }^{5,6,9-11}$ This occurrence must be investigated, since not observing a canal during endodontic therapy is a major cause of treatment failure. ${ }^{7}$

According to the literature, ${ }^{8-10,12-17}$ the observation of two canals in maxillary first molars ranges from 0 to $5.50 \%$, and the observation of two independent foramens from 0 to $4 \%$. On the contrary, there have been few studies focusing on the prevalence of this atypical occurrence in maxillary second molars, ${ }^{14,16,18}$ although several case reports have been described. Table 1 presents the results of studies showing the prevalence of two root canals and two foramens in the palatal root of maxillary first and second molars.

The knowledge of tooth internal anatomy must be considered during clinical and radiographic examinations. This should be valued not only to find atypical canals, but also to enable calcified canals cleaning and shaping, once they are frequently omitted during endodontic therapy.

The clinical challenge of finding the second palatal canal is clear when the results of ex vivo studies ${ }^{12,14,16,17}$ are compared with the ones of in vivo studies. ${ }^{12,15,18}$ Clinical studies have lower rates of occurrence of two canals in the palatal root of maxillary molars (Table 1).

For this reason, it is of utmost importance the obtainment of expulsive endodontic access, allowing for the visualization and inspection of the entire pulp chamber floor.
Recently, the clinical use of microscopy has been emphasized as an aid in the localization of calcified canals and in the identification of anatomical variations. ${ }^{19}$ This tool can be especially useful when it is possible to identify independent entrances for each canal, as observed in case reports 1 and 3 .

However, the presence of an atypical canal not observed on the pulp chamber floor may occur. In case report 2, the second palatal canal was identified as a ramification, once its entrance was situated at the cervical-third, being at least $3 \mathrm{~mm}$ distant from the pulp chamber floor. In such cases, the use of endodontic files can help to evaluate, in detail, the entire canal walls, leading to the identification of atypical morphologies. The presence of two distinct palatal roots must also be sought. Case report 5 is a good example of this unusual occurrence.

In case report 4, the presence of a second and third canal, with independents foramens in the palatal root is an unusual morphology. Neelakantan et $\mathrm{al}^{20}$ found $0.5 \%$ of 205 maxillary second molars in an Indian population studied.

Furthermore, recent studies have suggested the use of cone-beam or spiral computed tomography scans as a valuable method for the identification of the internal morphology. Especially when in doubt, these tools can provide a better understanding of the complex root canal anatomy. ${ }^{12,21-23}$

In case reports 1 and 2, palatal canals showed distinct apical foramens. Accordingly, the occurrence of two separate foramens has been described in most of the cases in which an extra canal is observed in the palatal root. ${ }^{8,12,14,16-17}$ On the contrary, occurrences of independent foramens in the mesiobuccal root, as observed in case report 2, can be detected in about $40 \%$ of the cases. ${ }^{12}$

The occurrence of independent foramens increases the chances of failure in cases of missing canals during

\begin{tabular}{|c|c|c|c|c|}
\hline Reference & $\begin{array}{l}\text { Number of teeth } \\
\text { in study }\end{array}$ & Method & Two canals (\%) & Two foramens (\%) \\
\hline \multicolumn{5}{|l|}{ Maxillary first molar } \\
\hline \multirow[t]{3}{*}{ Baratto-Filho et al ${ }^{12}$} & 291 & In vivo & 0.65 & 0.65 \\
\hline & 140 & Ex vivo & 2.05 & 2.05 \\
\hline & 54 & $\mathrm{CBCT}^{\dagger}$ & 4.55 & 4.55 \\
\hline Sert and Bayirli ${ }^{8}$ & 200 & Ex vivo & 5.50 & 4.0 \\
\hline Alavi et $\mathrm{al}^{13}$ & 52 & Ex vivo & - & - \\
\hline Al Shalabi et $a^{14}$ & 83 & Ex vivo & 1.20 & 1.20 \\
\hline Zaatar et al ${ }^{15}$ & 133 & In vivo & - & - \\
\hline Calişkan et al ${ }^{16}$ & 100 & Ex vivo & 3.28 & 3.28 \\
\hline Thomas, Moule, Bryant ${ }^{17}$ & 216 & Ex vivo & 2.30 & 1.80 \\
\hline \multicolumn{5}{|l|}{ Maxillary second molar } \\
\hline Al Shalabi et al $^{14}$ & 40 & Ex vivo & - & - \\
\hline Calişkan et al ${ }^{16}$ & 100 & Ex vivo & 2.08 & 2.08 \\
\hline
\end{tabular}

${ }^{\dagger} \mathrm{CBCT}$ : Cone-beam computed tomography 
endodontic treatment. For this reason, this possibility should be taken into account when apparently well-conducted endodontic therapy fails. ${ }^{5}$

\section{CONCLUSION}

The knowledge regarding the root canal anatomy and its variations must guide the planning and the technical implementation of endodontic treatment.

\section{CLINICAL SIGNIFICANCE}

Such knowledge may also contribute on further diagnostic hypotheses for failures. The presence of two canals in the palatal root of maxillary molars, as well as the presence of two distinct palatal roots, although rare, should be investigated.

\section{REFERENCES}

1. Degerness RA, Bowles WR. Dimension, anatomy and morphology of the mesiobuccal root canal system in maxillary molars. J Endod 2010;36:985-89.

2. Bond JL, Hartewell G, Portwell FR. Maxillary first molar with six canals. J Endod 1988;14:258-60.

3. Buhrley LJ, Barrows MJ, BeGole EA, Wenckus CS. Effect of magnification on locating the MB2 canal in maxillary molars. J Endod 2002;28:324-27.

4. Cleghorn BM, Christie WH, Dong CC. Root and root canal morphology of the human permanent maxillary first molar: A literature review. J Endod 2006;32:813-21.

5. de Almeida-Gomes F, Maniglia-Ferreira C, dos Santos RA. Two palatal root canals in a maxillary second molar. Aust Endod J 2007;33:82-83.

6. Deveaux E. Maxillary second molar with two palatal roots. J Endod 1999;25:571-73.

7. Wolcott J, Ishley D, Kennedy W, Johnson S, Minnich S. Clinical investigation of second mesiobuccal canals in endodontically treated and retreated maxillary molars. J Endod 2002;28:477-79.

8. Sert S, Bayirli GS. Evaluation of the root canal configurations of the mandibular and maxillary permanent teeth by gender in the Turkish population. J Endod 2004;30:391-98.

9. Pasternak Junior B, Teixeira CS, Silva RG, Vansan LP, Sousa Neto. Treatment of a second maxillary molar with six canals. Aust Endod J 2007; 33:42-45.

10. Maggiore F, Jou YT, Kim S. A six-canal maxillary first molar: A case report. Int Endod J 2002;35:486-91.

11. Karthikeyan K, Mahalaxmi S. New nomenclature for extra canals based on four reported cases of maxillary first molars with six canals. J Endod 2010;36:1073-78.

12. Baratto-Filho F, Zaitter S, Haragushiku GA, de Campos EA, Abauabara A, Correr GM. Analysis of the internal anatomy of maxillary first molars by using different metthods. J Endod 2009;35:337-42.

13. Alavi AM, Opasanon A, Ng YL, Gulabivala K. Root and canal morphology of Thai maxillary molars. Int Endod J 2002;35: 478-85.

14. Al Shalabi RM, Omer OE, Glennon J, Jennings M, Claffey NM. Root canal anatomy of maxillary first and second permanent molars. Int Endod J 2000;33:405-14.

15. Zaatar EI, al-Kandari AM, Alhomaidah S, al-Yasin IM. Frequency of endodontic treatment in Kuwait: Radiographic evaluation of 846 endodontically treated teeth. J Endod 1997;23:453-56

16. Caliskan MK, Pehlivan Y, Sepetçioglu F, Türkün M, Tuncer SS. Root canal morphology of human permanent teeth in a Turkish population. J Endod 1995;21:200-04.

17. Thomas RP, Moule AJ, Bryant R. Root canal morphology of maxillary permanent first molar teeth at various ages. Int Endod J 1993;26:257-67.

18. Holderrieth S, Gernhardt CR. Maxillary molars with morphologic variations of the palatal root canals: A report of four cases. J Endod 2009;35:1060-65.

19. Kontakiotis EG, Tzanetakis GN. Four canals in the mesial root of a mandibular first molar. A case report under the operating microscope. Aust Endod J 2007;33:84-88.

20. Neelakantan P, Subbarao C, Ahuja R, Subbarao CV, Gutmann JL. Cone-beam computed tomography study of root and canal morphology of maxillary first and second molars in an Indian population. J Endod 2010;36:1622-27.

21. Sponchiado EC, Ismail HA, Braga MR, de Carvalho FK, Simões CA. Maxillary central incisor with two root canals: A case report. J Endod 2006;32:1002-04.

22. Ballal S, Sachdeva GS, Kandaswamy D. Endodontic management of a fused mandibular second molar and paramolar with the aid of spiral computed tomography: A case report. J Endod 2007;33:1247-51.

23. Aggarwal V, Singla M, Logani A, Shah N. Endodontic management of a maxillary first molar with two palatal canals with the aid of spiral computed tomography: A case report. J Endod 2009;35:137-39.

\section{ABOUT THE AUTHORS}

\section{Roberta Kochenborger Scarparo}

Postdoctoral Researcher, Department of Clinical Dentistry, Pontifical Catholic University of Rio Grande do Sul, Brazil

\section{Letícia Pereira}

Specialist in Endodontics, Department of Dentistry, Brazilian Air Force Hospital of Canoas, Brazil

\section{Diana Moro}

Specialist in Endodontics, Department of Dentistry, Brazilian Air Force Hospital of Canoas, Brazil

\section{Grasiela Gründling}

PhD Student, Department of Clinical Dentistry, Pontifical Catholic University of Rio Grande do Sul, Brazil

\section{Maximiliano Gomes}

PhD Student, Department of Conservative Dentistry, Federal University of Rio Grande do Sul, Brazil

\section{Fabiana Soares Grecca}

Professor, Department of Conservative Dentistry, Federal University of Rio Grande do Sul, Brazil

\section{CORRESPONDING AUTHOR}

Roberta Kochenborger Scarparo, Av Ipiranga 6681, Prédio 6, CEP 90619900, Porto Alegre, RS, Brazil, e-mail: robks@terra.com.br 